\title{
Simulation of soil moisture for typical plain region using the Variable Infiltration Capacity model
}

\author{
ZHIYONG WU', YUN MAO', GUIHUA LU² \& JIANHUA ZHANG ${ }^{\mathbf{1}, 3}$ \\ 1 National Engineering Research Center of Water Resources Efficient Utilization and Engineering Safety, College of \\ Hydrology and Water Resources, Hohai University, No.1 Xikang Road, Nanjing, Jiangsu Province, China \\ wzyhhu@gmail.com \\ 2 National Engineering Research Center of Water Resources Efficient Utilization and Engineering Safety, Hohai \\ University, No.1 Xikang Road, Nanjing, Jiangsu Province, China \\ 3 Department of Water Resources of Jiangsu Province, Nanjing, China
}

\begin{abstract}
Droughts have a severe impact on the development of the social economy in developed plain areas. Soil moisture is a good index, it can reasonably reflect changes in drought. In this study, Jiangsu province in the Yangtze River Plain was selected as the research region, and the VIC (Variable Infiltration Capacity) large-scale hydrological model was selected to simulate the daily soil moisture with a resolution of $0.125 \times$ 0.125 degree from 1956 to 2009 . The simulated soil moisture was verified by measured soil moisture. The results indicate that the simulated soil moisture distribution is relatively consistent for the three soil layers $(0-20,20-100$ and $0-100 \mathrm{~cm})$, showing an increasing trend from northwest to southeast. The simulated soil moisture anomalies agreed well with in situ observations. The simulated soil moisture data thus can be used to analyze the spatio-temporal variation of the regional water content and to provide support for drought monitoring and forecasting.
\end{abstract}

Key words soil moisture; the VIC model; Jiangsu Province, China; plain

\section{INTRODUCTION}

Jiangsu province is a typical area of frequent droughts and floods located in Jianghuai region (Yang and Li, 2003). In recent years, large-scale and high-impact drought events have occurred continuously under the combined effects of warming and human activities (Liu et al., 2006). Frequent occurrence of drought events not only brings great pressure to agriculture and people's daily lives, but also seriously affects the normal conduct of industrial production. Drought has been the important limiting factor of the economic and social development of Jiangsu province (Feng and Wang, 2002). As the key variable in the development of drought events (Wu et al., 2012), soil moisture has important application value for analysing the variation of drought and for drought monitoring and forecasting.

Large-scale and long sequences of measured soil moisture data are difficult to acquire, but soil moisture can be simulated by using land surface hydrological models based on meteorological data. The variable infiltration capacity (VIC) model is a typical land surface hydrological model. It has been successfully applied to simulate soil moisture over the whole nation (Wu et al., 2007, 2012; Kuang et al., 2012; Lu et al., 2013) and in basins at different scales (Zhang, 2006; Chen, 2010; Lu et al., 2013; Zhang et al., 2013). Existing research (Liu, 2004; Song et al., 2007; Lin et al., 2008; Ma et al., 2013) mainly focuses on areas for which parameters can be easily calibrated. The applicability of simulated soil moisture in the plain region still remains to be further studied. For this reason, Jiangsu province in the Yangtze River Plain was selected as the research region. The VIC model was built for a typical plain region, and the parameters were determined by using the parameter transfer formula combining regional hydrological parameters, remote sensing images and soil data. The spatial distribution characteristics of the simulated soil moisture from 1956 to 2009 were analysed, and the simulated soil moisture was verified by soil moisture measured at Xuzhou and Zhenjiang stations from 1981 to 1999 in Jiangsu province. 


\section{MATERIALS AND METHODS}

\subsection{Study area and materials}

Jiangsu is an eastern coastal province of China $\left(116.3^{\circ}-121.95^{\circ} \mathrm{E}, 30.75^{\circ}-35.33^{\circ} \mathrm{N}\right)$, extending over $102600 \mathrm{~km}^{2}$ (Fig. 1). Plains account for over $70 \%$ of the area.

This study used the daily temperature and precipitation data from 32 meteorological stations and 81 raingauge stations for 1956-2011. The data are derived from the China Meteorological Data Sharing Service System and Jiangsu Province Hydrology and Water Resources Investigation Bureau. According to the Impact of Climate Change on Jiangsu Water Resources and Strategy project, soil moisture was simulated based on the time step of $24 \mathrm{~h}$, and the water balance was calculated only at the resolution of $0.125^{\circ} \times 0.125^{\circ}$ in the VIC model. The distribution of grids and stations in Jiangsu Province are shown in Fig. 1. The station data were estimated on the $0.125^{\circ}$ grid using the inverse distance weighted method.

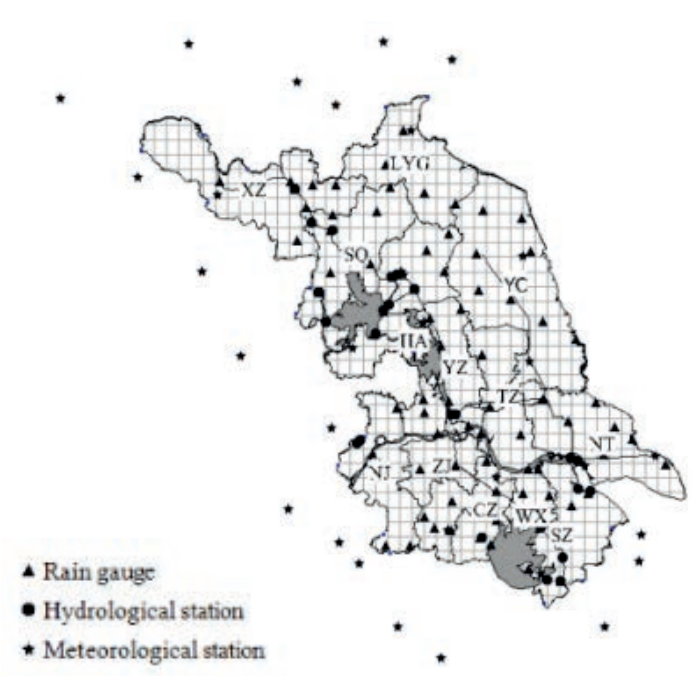

Fig. 1 Distribution of grids, meteorological stations and raingauge stations in Jiangsu Province.

\subsection{The VIC model and determination of parameters}

The VIC model is a semi-distributed macroscale hydrological model. The principal of the VIC model is explained with details in Liang et al. (1996). The parameters of VIC can be divided into four categories: geography parameters, vegetation parameters, soil parameters and hydrological parameters. The geography parameters are calculated by meteorological variables and the location of the research region. The vegetation parameters are determined by vegetation classes. The soil parameters can be directly calculated combined with looking up from tables based on soil types. Once determined, these three parameters do not change when the model has been built.

The hydrological parameters are difficult to determine directly due to the complex and changeable process of runoff. It should be calibrated by hydrological data measured in the basin, or be transferred by using the parameter transfer formula. The regression relations between hydrological parameters and the meteorological and soil factors can be used for the parameter determination, as detailed in $\mathrm{Wu}$ et al. (2007). There are two sets of the parameter transfer formula that have been established in China (Lu et al., 2010, 2013). One set is the nation-wide parameter transfer formula (NPTF), which was established according to the soil and climate of the 35 calibrated basins over China (Lu et al., 2010). Another one is the southern part of China parameter transfer formula (SPTF), which was built using data for 49 calibrated basins located in the south region of China (Lu et al., 2013). The stepwise regression method was applied to analyse the relationship between hydrological parameters and soil, climate, topography and vegetation. 
Its location in the north-south climate and sea-land connecting zone results in the unique climate of Jiangsu basin. Moreover, the province is situated in the downstream of the Yangtze and Huai rivers, low and flat with interleaved rivers. The special climate and geography result in new requirements for determining hydrological parameters. There are 151 stream gauging stations, 258 gauging stations and 37 drainage water stations in Jiangsu, but most of them are gate dam stations or main control stations without closed flow measurement. It is hard to calibrate the hydrological parameters based on observations. Furthermore, most of the calibrated basins chosen above are in mountainous areas. So further verification needs to be done of their applicability to the plain region. In this study, the reasonability of the parameters derived from the calculation based on the two formulas (NPTF and SPTF) was analysed considering the local soil, vegetation and landform characteristics. Hydrological parameters were adjusted to determine the adopted ones, and the results are shown in Table 1. For each grid, the adopted parameter was selected from the value calculated by NPTF or SPTF, according to its geology and geography.

Table 1 Regional average parameters of each scheme.

\begin{tabular}{lllllll}
\hline Hydrological Parameter & B & Ds & Dmax & Ws & D2 & D3 \\
\hline Calculated by NPTF & 0.062 & 0.090 & 16.576 & 0.832 & 0.976 & 0.485 \\
Calculated by SPTF & 0.216 & 0.139 & 6.532 & 0.921 & 0.204 & 0.298 \\
Adopted & 0.071 & 0.093 & 5.419 & 1.000 & 0.245 & 0.501 \\
\hline
\end{tabular}

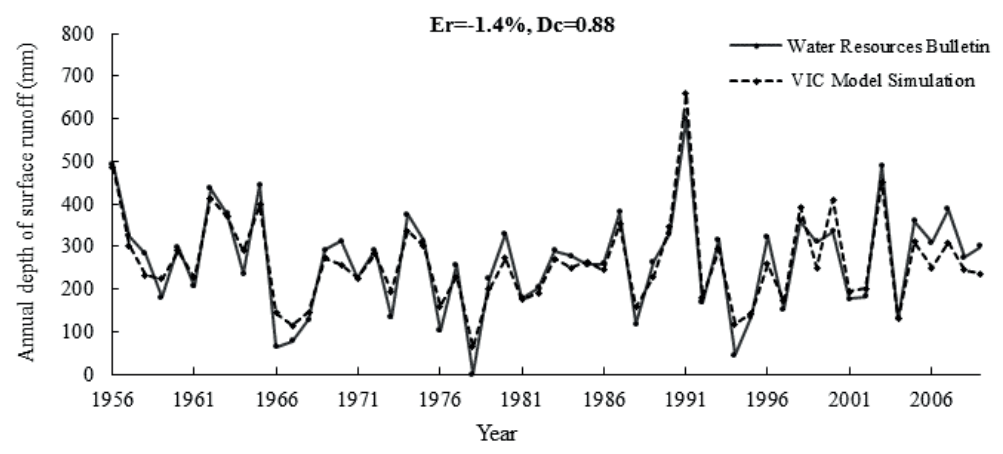

Fig. 2 Comparison of annual runoff simulated by VIC and that published by JWRB for Jiangsu province during 1956-2009.

To validate the VIC model, the annual runoff data from Jiangsu Water Resources Bulletin (JWRB) was used. Figure 2 shows the annual runoff of Jiangsu Province during 1956-2009 modelled by VIC and that published by JWRB. It shows that the simulation results of VIC were very close to the data from JWRB. Their average values were $265 \mathrm{~mm}$ and $262 \mathrm{~mm}$ respectively, and the relative error was $-1.4 \%$. But data simulated by VIC were smaller than that published in JWRB. Both of the datasets fit well with the annual discharge process and their determination coefficient came to 0.88 . The annual average absolute relative error was $18 \%$, but there were six years (1978, 1994, 1966, 1967, 1973 and 1976) whose relative errors were greater than 40\%, these were all drought years. The main reason for the great difference was that the calculation methods of the VIC model used to express rainfall-runoff transformation relations in dry years were different from that of JWRB. On the whole, the model established in this paper was rational and feasible.

\section{RESULTS AND ANALYSIS}

\subsection{Rationality analysis of simulated soil moisture}

As the thickness of soil layers is inhomogeneous, the soil moisture from stations (area $<0.005 \mathrm{~km}^{2}$ ) is usually quite different from the average simulated values of grids (area $<500 \mathrm{~km}^{2}$ ), use of the 
latter directly in research is questionable. However, some scholars have proposed that the rationality of the simulated soil moisture can be verified by contrasting the simulated anomaly with the observed.

We contrasted the process and correlation coefficients between the measured and simulated soil moisture anomalies for Zhenjiang station and Xuzhou station. The anomaly is computed as follows:

$$
y_{i}=x_{i}-\bar{x}_{i}
$$

where $x_{i}$ and $\bar{x}_{i}$ represent the current value of soil moisture and its climatology respectively.

Statistically, the correlation coefficients of the $0-20 \mathrm{~cm}$ soil layer were 0.75 for both stations, those of the $20-100 \mathrm{~cm}$ soil layer were 0.62 and 0.67 at Zhenjiang and Xuzhou stations, while those of the $0-100 \mathrm{~cm}$ soil layer were 0.67 and 0.72 , respectively. It can be seen that the stimulated values were reliable. The soil moisture anomalies and correlation coefficients $(r)$ are shown in Fig. 3, for the simulated and measured data of the $0-100 \mathrm{~cm}$ soil layer. We can see that the variability of simulated soil moisture reflects the gains and losses of the measured data well, with a significant fitting effect.

There was a significant correlation between the simulated and measured soil moisture anomalies with a good fitting process line. The stimulated soil moisture data can be used for analysis of the temporal and spatial variation character of measured soil moisture.
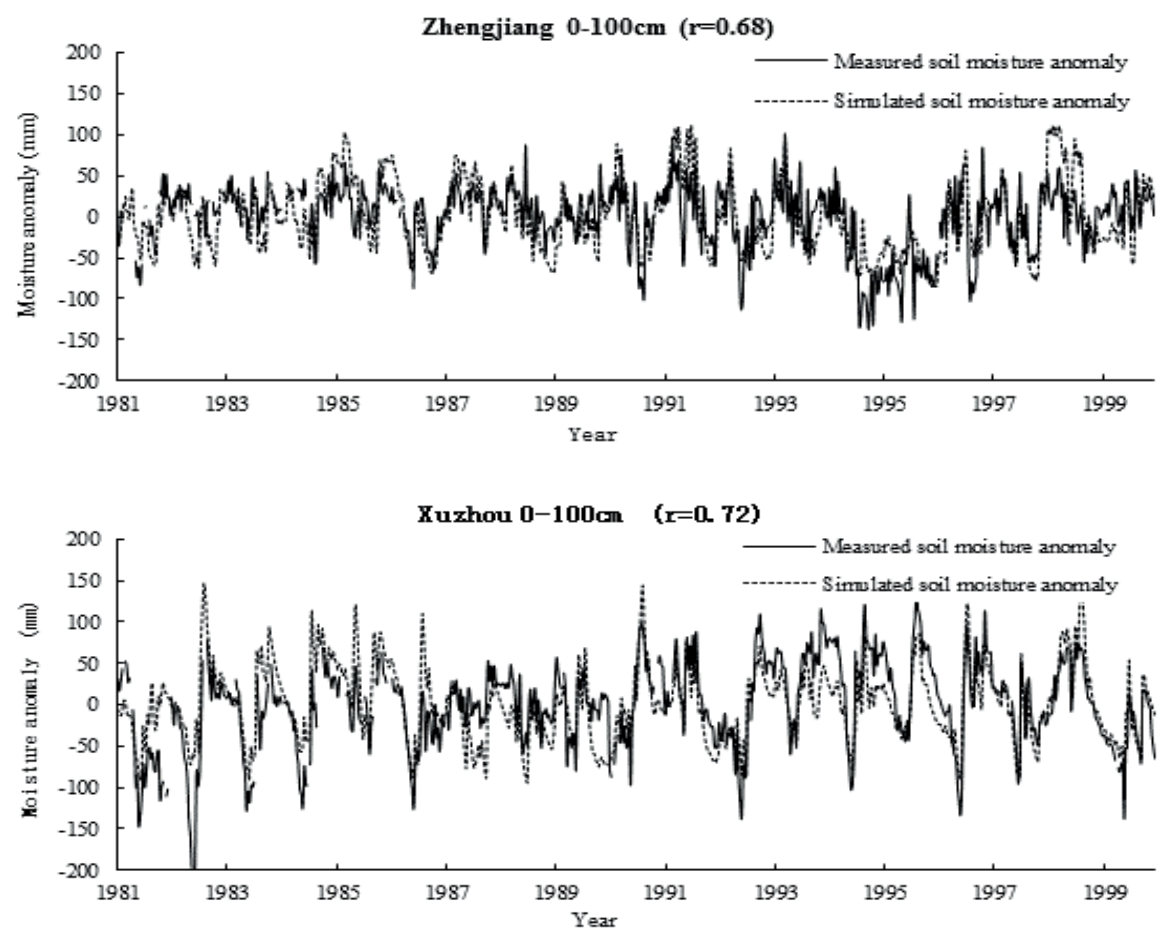

Fig. 3 Comparison of simulated (dashed) and measured (solid) soil moisture anomalies (mm) for $0-100 \mathrm{~cm}$ depth at Zhenjiang and Xuzhou.

\subsection{Simulated soil moisture of Jiangsu province}

Figure 4 shows the spatial distributions of simulated soil moisture of Jiangsu province. SM1 and SM2 stand for soil moisture content of the shallow, 0-20 cm, and deep, 20-100 cm, layers respectively, and SM3 for the whole profile, $0-100 \mathrm{~cm}$. Mean values of SM1, SM2 and SM3 were $71.6,303.9$ and $375.5 \mathrm{~mm}$ respectively. The spatial variation range of soil moisture was large; for SM1, SM2 and SM3 values were 45.2-173.7, 145.1-795.4 and 190.4-969.1 mm, respectively. 

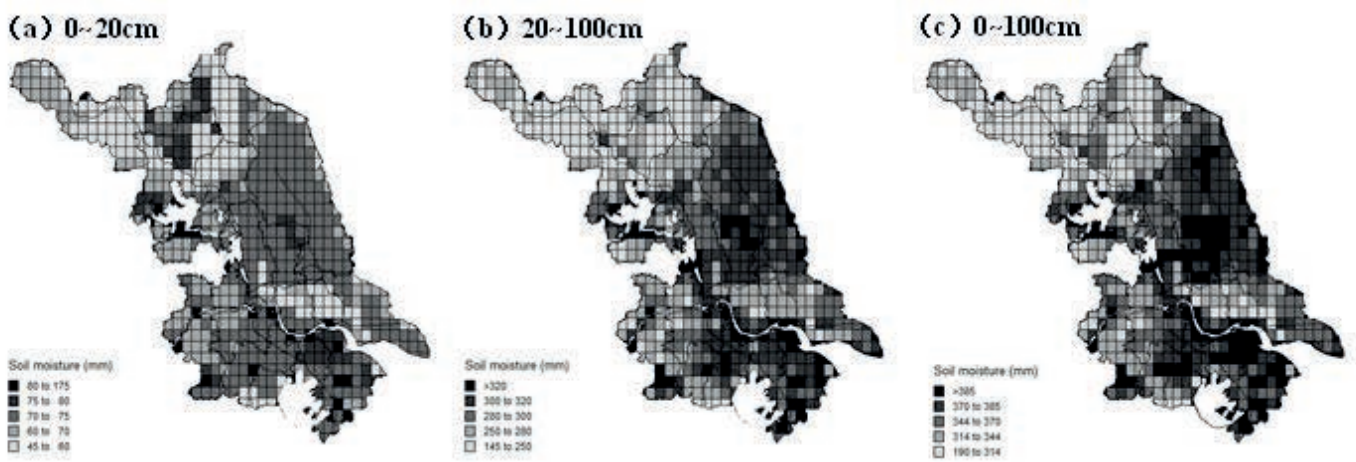

Fig. 4 Spatial distributions of simulated soil moisture of Jiangsu province.

From Fig. 4 we can see that simulated soil moisture of each layer shows gradually increasing characteristics from northwest to southeast. Among them, high value "centres" of soil moisture occur in northern Suzhou and the border area of Taizhou and Yancheng city. The value at Nantong city was lower than that of surrounding areas, yet there are also lower levels in north Jiangsu cities like Xuzhou, Lianyungang and Suqian.

Figure 5 is the inter-annual variation hydrograph of SM3. The average annual SM3 fluctuated between 328.0 and $417.2 \mathrm{~mm}$. From the flat trend lines we can see that the change of annual soil moisture was not significant in the recent 54 years, but SM3 varied a lot between years. The SM3 values were low in 1956, 1967, 1978, 1995 and 2002, indicating the years were dry. While values were large in wet years $(1963,1975,1985,1991,2000$, etc.). The results conform to the actual conditions.

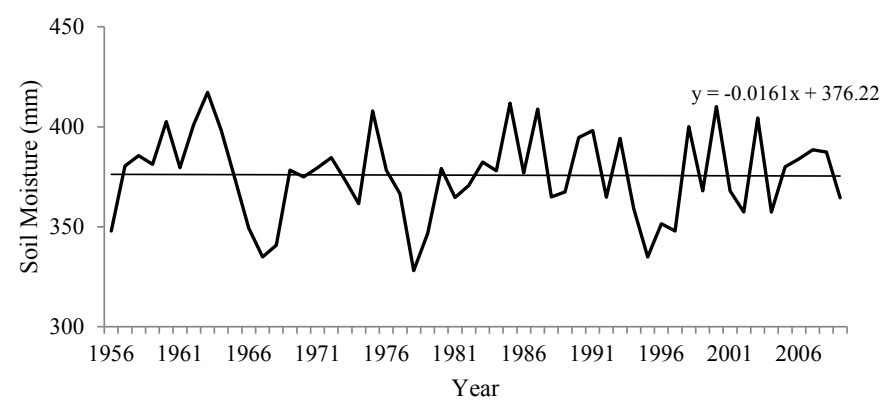

Fig. 5 Long-term change of SM3 in Jiangsu province.

\section{CONCLUSION}

The VIC model was driven by the daily precipitation, the daily maximum and minimum air temperature to generate the daily soil moisture of Jiangsu province from 1956 to 2009 in this paper, and the simulated soil moisture was verified by measured soil moisture over the same period. The results obtained are as follows:

(1) Parameters of the VIC model were determined by using the parameter transfer formula, and annual runoff simulated by the VIC model was close to the data of JWRB. So the VIC model built in this study was feasible.

(2) Simulated and measured soil moisture anomalies had good correlation; the shallow layer had the best correlation. Simulated soil moisture can well reflect the gains and losses of soil moisture and so can be used for actual analysis of soil moisture in Jiangsu province.

(3) Spatial distributions of the simulated SM1, SM2 and SM3 were consistent, showing an increase from the northwest to southeast, and SM2 varied in a large range. 
The soil moisture database generated in this paper is a new attempt to simulate soil moisture in grids of $0.125 \times 0.125$ degree by the VIC model in Jiangsu province. This database will be helpful for further study on the change regulations of drought in Jiangsu province, providing scientific evidence for policy-making.

Acknowledgement This work is supported by the Natural Science Foundation of Jiangsu Province of China (Grant no. BK20131368), the Special Public Sector Research Program of Ministry of Water Resources (Grants no. 201301040 and 201401008), the Foundation for the Author of National Excellent Doctoral Dissertation of PR China (Grant no. 201161), the Qing Lan Project and Program for New Century Excellent Talents in University(Grant no. NCET-12-0842).

\section{REFERENCES}

Chen, X.F. (2010) Application research of VIC model to Bailian Region. Yellow River 1, $37-38$.

Feng, P. and Wang, Z. Y. (2002) On the drought hazard and its management in China. Journal of Catastrophology 1, 2-5+26.

Kuang, Y.H., Lu, G.H. and Wu, Z.Y. (2012) Analysis on spatial-temporal characteristics of simulate soil moisture in nearly 60 years of China. New development of Hydrological Science - 2012 China Symposium on Hydrology.

Liang, X., Wood, E.F. and Lettenmaier, D.P. (1996) Surface soil moisture parameterization of the VIC-2L model: Evaluation and modification. Global and Planetary Change 13(1), 195-206.

Liu, D.X., Bai, H.Z. and Ning, H.F., (2006) Response of arid meteorological disaster to climatic warming in Gansu Province Journal of Glaciology and Geocryology 5, 707-712.

Lu, G.H., et al. (2013) Spatial and temporal characteristic of soil moisture in different climatic regions of China. China Rural Water and Hydropower 5, 15-19.

Lu, G.H., Wu, Z.Y. and He, H. (2010) Hydrological Cycle and the Quantitative Prediction. Beijing: Science Publishing House.

Lu, G.H., et al. (2013) Parameter gridding formulas of VIC Model in Southern region of China and effect verification. Water Resources and Power 5, 13-17.

Lin, J., Xie, Z.H. and Chen, F. (2008) Simulation of VIC hydrologic model during 2006 flood season. Meteorological Monthly 3, 69-77.

Liu, Q. (2004) An Application of Infiltration Capacity (VIC) Macro Seale Land Surface Hydrological Model in China. MSc Thesis, Hunan University.

Ma, H., Jiang, S.H. and Ren, L.L. (2013) Variation of annual runoff and sediment distribution in Ganjiang River basin over past 50 years. Journal of China Hydrology 3, 52-55.

Song, X.Y., Yu, H.Y. and Zhang, L.D. (2007) Application of VIC land surface hydrological model in flow simulation of Bailian River Basin. Journal of China Hydrology 2, 40-44.

Wu, Z.Y., et al. (2012) Drought monitoring technology based on simulation of soil moisture. Journal of Hohai University (Natural Sciences) 1, 28-32.

Wu, Z.Y., et al. (2007) Simulation of daily soil moisture using VIC Model. Scientia Geographica Sinica 3, $359-364$.

Yang, H. and Li, C. Y. (2003) The relation between atmospheric intraseasonal oscillation and summer severe flood and drought in the Changjiang-Huaihe River basin. Advances in Atmospheric Sciences 4, 540-553.

Zhang, L.L., Hao, Z.C. and Tong, K. (2013) Application of VIC model to runoff simulation of Three-source Region. Water Resources and Power 1, 18-20+239.

Zhang, X.J. (2006) Application Research on VIC model in Chinese Humid Areas. MSc Thesis, Hohai University. 